\title{
A diet with a struvite relative supersaturation less than 1 is effective in dissolving struvite stones in vivo
}

\author{
Doreen M. Houston $^{1 *}$, Heather E. Weese ${ }^{1}$, Michelle D. Evason ${ }^{1}$, Vincent Biourge ${ }^{2}$ \\ and Ingrid van Hoek $^{2}$ \\ ${ }^{1}$ Medi-Cal Royal Canin, Guelph, ON, Canada \\ ${ }^{2}$ Royal Canin Research Center, Aimargues, France
}

(Received 22 October 2010 - Revised 10 January 2011 - Accepted 28 January 2011)

\begin{abstract}
Magnesium ammonium phosphate (struvite) is one of the most common minerals found in feline uroliths. Previous studies have shown the efficacy of acidifying calculolytic diets (inducing urine $\mathrm{pH}<6.5$ ), in dissolving struvite stones in cats. Recent work in our laboratory found that wet and dry test diets induce a struvite urinary relative supersaturation (RSS) $<1$ and that the urine of healthy cats fed the dry test diet dissolved feline struvite stones in vitro. The objective of the present study was to demonstrate the efficacy of those test diets on naturally occurring struvite urocystoliths in cats. A total of twenty-one cats were used, of which seventeen completed the study. Of the seventeen cats, eight were fed the wet test diet and nine the dry test diet. Uroliths dissolved in a median of 18 (10-55) d. In the remaining four cats, uroliths failed to dissolve and were removed surgically. Quantitative analysis showed that these uroliths contained either calcium oxalate or calcium phosphate. The present study demonstrates that diets that induce a struvite RSS $<1$ result in struvite stone dissolution in vivo.
\end{abstract}

Key words: Feline: Dissolution: Struvite: Relative supersaturation

In cats, the majority of uroliths found in the bladder are composed of magnesium ammonium phosphate (struvite) or calcium oxalate ${ }^{(1-3)}$. Surveys on the prevalence of struvite and calcium oxalate uroliths in stone laboratories worldwide indicate that the occurrence of those two stones represents approximately $95 \%$ of submissions. Struvite and calcium oxalate are more or less equally represented, with a slight advantage to one of them depending on the country ${ }^{(1-8)}$.

The most important risk factors for struvite formation are urinary $\mathrm{pH}$ and urine dilution, which will affect the concentrations of magnesium, ammonium and phosphate ${ }^{(4)}$. Contributing factors to struvite uroliths in cats may include periods of inclement weather in which cats tend to remain indoors for prolonged periods of time, inactivity, and feeding of low moisture, non-acidifying dry cat foods ${ }^{(9)}$. In a retrospective case-control study, diets with high $\mathrm{Mg}, \mathrm{P}, \mathrm{Ca}, \mathrm{Cl}$ and fibre, moderate protein and low fat content were associated with increased risk ${ }^{(10)}$.

Previous studies have shown the efficacy of canned ${ }^{(11,12)}$ and dry ${ }^{(12)}$ urine-acidifying diets in dissolving feline struvite stones. A study in our laboratory has found that the urine of healthy cats fed a dry-extruded diet, formulated to generate a urinary struvite relative supersaturation (RSS) $<1$, dissolved feline struvite uroliths in vitro ${ }^{(13)}$. Therefore, the present study was undertaken to confirm that diets inducing struvite RSS $<1$ and effective in dissolving struvite stones in vitro were also effective in dissolving naturally occurring struvite stones in vivo.

\section{Materials and methods}

Cats were recruited from veterinary hospitals across Canada. They entered the study on the basis of clinical signs of lower urinary tract disease including, but not limited to, haematuria, stranguria, pollakiuria, inappropriate urination and radiographic evidence of radiodense uroliths. Parameters at inclusion included a complete blood cell count, serum biochemistry, urinalysis, aerobic urine culture and survey abdominal radiographs by the local veterinarian. The presence of struvite crystals was not necessary for inclusion. Urine culture and sensitivity were performed on all cats. Attending veterinarians were requested to perform cystocentesis and administer antibiotics based on culture and sensitivity results. Exclusion criteria included the presence of significant disease such as renal failure, presence of uroliths in the ureters or urethra, and evidence suggesting that the stones may be composed of other mineral types. Radiographs and urinalysis were repeated on a weekly basis and evaluated by two

Abbreviation: RSS, relative supersaturation.

* Corresponding author: D. M. Houston, fax +1 800290 0593, email dhouston@mcrcvetdiets.ca 
Table 1. Key parameters of the diet (dry or wet) fed

\begin{tabular}{|c|c|c|}
\hline & Dry diet* & Wet diet (loaf) $\dagger$ \\
\hline RSS-MAP & 0.2 & 0.3 \\
\hline RSS-oxalate & $<5$ & $<5$ \\
\hline Protein $(\mathrm{g} / 4184 \mathrm{~kJ})$ & 89.4 & $82 \cdot 1$ \\
\hline Fat $(\mathrm{g} / 4184 \mathrm{~kJ})$ & $40 \cdot 2$ & $59 \cdot 7$ \\
\hline Crude fibre $(\mathrm{g} / 4184 \mathrm{~kJ})$ & $6 \cdot 2$ & 8 \\
\hline $\mathrm{Na}(\mathrm{g} / 4184 \mathrm{~kJ})$ & 3.5 & $2 \cdot 35$ \\
\hline$P(g / 4184 \mathrm{~kJ})$ & $2 \cdot 1$ & 1.97 \\
\hline$M g(g / 4184 \mathrm{~kJ})$ & 0.2 & 0.2 \\
\hline $\mathrm{K}(\mathrm{g} / 4184 \mathrm{~kJ})$ & $2 \cdot 7$ & $3 \cdot 2$ \\
\hline Total $n-3$ (g/4184 kJ) & 1.3 & 1.71 \\
\hline EPA:DHA & 0.65 & $1 \cdot 17$ \\
\hline$M E(\mathrm{~kJ} / \mathrm{kg}$ as fed $) \ddagger$ & 3861 & 938 \\
\hline $\begin{array}{l}\text { Base excess } \\
\quad \text { (cation-anion balance) } \\
\text { (4184 kJ ME) }\end{array}$ & $-50 \cdot 85$ & -39.58 \\
\hline
\end{tabular}

RSS, relative supersaturation; MAP, magnesium ammonium phosphate; ME, metabolisable energy.

* Veterinary Diet Urinary S/O, Guelph, Ontario, Canada, Urinary High Dilution (rest of the world), Royal Canin, Aimargues, France.

$\dagger$ Veterinary diet Urinary S/O wet, Royal Canin, Aimargues, France. 으 $\quad$ F $\begin{aligned} & \text { ME was measured by animal trials according to the American Association of } \\ & \text { Feed Control Officials protocol (2010). }\end{aligned}$

board-certified internal medicine specialists (D. M. H. and M. D. E.) to assess time of complete stone dissolution.

All cats in the present study were client-owned. The cats were maintained in their home environments and the attending veterinarian was responsible for case management. The owners were instructed to feed either the wet (Feline Veterinary diet, Urinary S/O; Royal Canin, Aimargues, France) or dry test diet (Feline Veterinary diet, Urinary S/O in North America and Urinary High Dilution in other areas of the World, Royal Canin, Aimargues, France) exclusively for the duration of the trial. No combination of the wet and dry diets was allowed. The owner determined which form of diet to feed their cat based on prior preferences. Key diet parameters are listed in Table 1.

If stones failed to dissolve within 12 weeks, surgery was performed and uroliths were analysed quantitatively at the Canadian Veterinary Urolith Centre (Guelph, ON, Canada). The study was reviewed and approved by the Ethics Committee of Royal Canin and owners gave informed consent for inclusion.

Data are expressed as medians and ranges. Results were analysed for effects of diet, sex and urine culture on time to dissolution using a Mann-Whitney $U$ test. These analyses were performed using an open statistical software (TANAGRA: TANGRA, Ricco Rakotomalala, Lyon, France, 2004, http://eric. univ-lyon $2 . \mathrm{fr} / \sim$ ricco/tanagra/).

\section{Results}

A total of twenty-one cats were used in the present study. Complete stone dissolution was observed in seventeen cats including thirteen spayed female and four neutered male cats. Stones in four cats failed to show radiographic change and were surgically removed. Quantitative analysis confirmed three of those stones to be calcium oxalate and one to be calcium phosphate.

Of the seventeen cats with complete dissolution, eight were fed the wet and nine the dry test diets, respectively. The median age was 5.5 (range 2-15) years (Table 2) and body weights 6.0 (range $3.5-11 \cdot 8$ ) kg. Struvite stones dissolved in a median time of $19(10-42) \mathrm{d}$ and $16(14-55) \mathrm{d}$ in cats fed dry or wet diet, respectively (Table 2$)$. No significant effect of sex $(P=0.4993)$ and form of diet $(P=0.8845)$ on time of dissolution was found.

It was found that six cats (35\%) had positive urine cultures. The median time to dissolution of uroliths in these cats was 21.5 (range 13-48) d compared with 15 (range 10-55) d for the negative cats; this difference was not significant $(P=0 \cdot 4790$; Table 2).

\section{Discussion}

High urine $\mathrm{pH}(>6.5)$ and concentrated urine are risk factors for struvite crystal and stone formation ${ }^{(14)}$. Over the past 10 years, urine RSS has been used to evaluate the ability of diets to generate an undersaturated urine (RSS <1) and thus their ability to prevent and dissolve struvite stones ${ }^{(14)}$ We have recently showed in our laboratory that feline struvite uroliths can be dissolved in vitro using urine from cats fed a diet generating a urinary struvite RSS $<1$, the dry test diet used in the present study ${ }^{(13)}$. RSS and in vitro studies are easier to perform than clinical trials but the efficacy of those measurements to assess the ability of a diet to dissolve naturally occurring struvite stones remains to be determined. Indeed, stone formers might have different urine composition than healthy controls. It has also been suggested that the presence of inhibitors and promoters of crystal formation and aggregation might be different in affected animals ${ }^{(1)}$.

Table 2. Time to dissolution of uroliths, age and weight of cats (all cats, cats fed the dry or wet diet only, and cats with or without positive urinary cultures) (Medians and ranges)

\begin{tabular}{|c|c|c|c|c|c|c|c|c|c|c|}
\hline \multirow[b]{2}{*}{ Variables } & \multicolumn{2}{|c|}{ All cats $(n 17)$} & \multicolumn{2}{|c|}{ Dry diet $(n 9)$} & \multicolumn{2}{|c|}{ Wet diet ( $n$ 8) } & \multicolumn{2}{|c|}{ 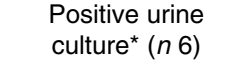 } & \multicolumn{2}{|c|}{$\begin{array}{l}\text { Negative urine } \\
\text { culture }(n 11)\end{array}$} \\
\hline & Median & Range & Median & Range & Median & Range & Median & Range & Median & Range \\
\hline Time to dissolution (d) & 18 & $10-56$ & 19 & $10-42$ & 16 & $14-55$ & 21.5 & $13-48$ & 15 & $10-55$ \\
\hline Age (years) & 5.5 & $2-15$ & $6 \cdot 0$ & $2-15$ & $5 \cdot 0$ & $3-13$ & $8 \cdot 3$ & $5-15$ & $5 \cdot 0$ & $2-13$ \\
\hline Weight (kg) & $6 \cdot 0$ & $3.5-11.8$ & $6 \cdot 0$ & $4 \cdot 5-7 \cdot 3$ & $6 \cdot 4$ & $3.5-11.8$ & 6.5 & $4.5-7.8$ & $5 \cdot 7$ & $3.5-11.8$ \\
\hline
\end{tabular}

* Of the six cats with positive urine cultures, two cats had Staphylococcus intermedius, one had Escherichia coli, one had Enterococcus, one had Klebsiella, and one had $S$. intermedius and $E$. coli. The time to dissolution between cats with a positive culture $v$. those with a negative culture was not significant. 
Both test diets used in the present study have been shown to induce in healthy cats a RSS $<1$ according to the protocol described by Robertson et al. ${ }^{(14)}$. Both these diets also induced complete dissolution of radio-dense uroliths in seventeen of the twenty-one cats. In the four cats in which no dissolution was observed, we established that the mineral composition was not struvite. Therefore, the present study strongly suggests that in vitro dissolution and struvite RSS measurements are good surrogate markers of in vivo efficacy. Although on a small number of patients, our data suggest that a well-formulated dry diet is as efficient in dissolving struvite stones as a wet diet.

Females were over-represented in the present dissolution study compared with previous dissolution studies ${ }^{(11,12)}$ and reviews on feline urolithiasis ${ }^{(3,5,7)}$. The weight and age of cats used in the present study were similar to those reported previously ${ }^{(1,3,5,7)}$.

In dogs, urinary tract infection is the most common cause of struvite uroliths ${ }^{(15)}$. Urinary tract infection as a cause of struvite uroliths has been reported as rare in cats (around $3 \%)$ except in the very young $(<1$ year) and old ones $(>10$ years $)^{(1,16,17)}$. In the present study, $35 \%$ of the cats had positive cultures on samples taken by cystocentesis and only one of those cats was more than 10 years of age. Of the six positive cats, three had urinary tract infections with known urease-splitting bacteria (Staphylococcus intermedius) that promotes alkaline urine as well as struvite crystal and stone formation. Time to dissolution in those three cats (13-48d) was not different from either the cats with no urea-splitting bacteria $(17-28 d)$ or the cats without bacteriuria $(10-55 d)$. The reason for this high prevalence of bacteriuria remains unclear and, in some cases, might be the result of contamination at the time of sampling or secondary infection due to the presence of the uroliths.

\section{Conclusion}

Our data strongly suggest that a diet designed to generate undersaturated urine for struvite (RSS $<1$ ) is effective for both in vivo and in vitro dissolution of struvite bladder stones. Screening diets based on their urine struvite RSS is a rapid and efficient way to assess their efficacy in the prevention and dissolution of naturally occurring struvite uroliths.

\section{Acknowledgements}

All authors are employees of Royal Canin and all contributed to the design of the study and preparation of the manuscript. The study was funded by Royal Canin. The authors would like to thank the Veterinary Clinics and their staff who contributed to the inclusion of the cases.

\section{References}

1. Osborne CA, Lulich JP, Kruger JM, et al. (2009) Analysis of 451,891 canine uroliths, feline uroliths, and feline urethral plugs from 1981 to 2007: perspectives from the Minnesota Urolith Center. pp. 183-197 [CA Osborne and JP Lulich, editors]. Philadelphia, PA: WB Saunders. Vet Clin North Am Small Anim Pract.

2. Cannon AB, Westropp JL, Ruby AL, et al. (2007) Evaluation of trends in urolith composition in cats: 5,230 cases (1985-2004). J Am Vet Med Assoc 231, 570-576.

3. Houston DM \& Moore AEP (2009) Canine and feline urolithiasis: a look at over 50,000 urolith submissions to the Canadian Veterinary Urolith Centre from February 1998 to August 2008. Can Vet J 50, 1263-1268.

4. Lekcharoensuk C, Osborne CA \& Lulich JP (2001) Epidemiologic study of risk factors for lower urinary tract diseases in cats. J Am Vet Med Assoc 218, 1429-1435.

5. Gerber B, Boretti FS, Lkey S, et al. (2005) Evaluation of clinical signs and causes of lower urinary tract disease in European cats. J Small Anim Pract 46, 571-577.

6. Stevenson AE (2001) The incidence of urolithiasis in cats and dogs and the influence of diet in the formation and prevention of recurrence. PhD Thesis. Institute of Urology and Nephrology, University College London.

7. Westropp JL, Buffington CAT \& Chew D (2005) Feline lower urinary tract disorders. In Textbook of Veterinary Internal Medicine, 6th ed., pp. 1828-1850 [SJ Ettinger and EC Feldman, editors]. St Louis, MO: Elsevier Saunders.

8. Houston DM, Moore AE, Favrin MG, et al. (2003) Feline urethral plugs and bladder uroliths: a review of 5484 submissions 1998-2003. Can Vet J 44, 974-977.

9. Jones BR, Sanson RL \& Morris RS (1997) Elucidating the risk factors of feline lower urinary tract disease. NZ Vet J $\mathbf{4 5}$, $100-108$.

10. Lekcharoensuk C, Osborne CA, Lulich JP, et al. (2001) Association between dietary factors and calcium oxalate and magnesium ammonium phosphate urolithiasis in cats. J Am Vet Med Assoc 219, 1228-1237.

11. Osborne CA, Lulich JP, Kruger JM, et al. (1990) Medical dissolution of feline struvite urocystoliths. J Am Vet Med Assoc 196, 1053-1063.

12. Houston DM, Rinkardt NE \& Hilton J (2004) Evaluation of the efficacy of a commercial diet in the dissolution of feline struvite bladder uroliths. Vet Therap 5, 187-201.

13. van Hoek I, Malandain E, Tournier C, et al. (2009) RSS is a better predictor for struvite dissolution than urine $\mathrm{pH}$. Vet Focus 19, 47-48.

14. Robertson W, Jones J, Heaton M, et al. (2002) Predicting the crystallization potential of urine from cats and dogs with respect to calcium oxalate and magnesium ammonium phosphate (struvite). J Nutr 132, 1637S-1641S.

15. Seaman R \& Bartges JW (2001) Canine struvite urolithiasis. Comp Contin Educ Pract Vet 23, 407-429.

16. Osborne CA, Kruger JM, Lulich J, et al. (2000) Feline lower urinary tract diseases. In Textbook of Veterinary Internal Medicine, 5th ed., pp. 1710-1747 [SJ Ettinger and EC Feldman, editors]. Philadelphia, PA: WB Saunders Company.

17. Lekcharoensuk C (2000) Association between patient-related factors and risk of calcium oxalate and magnesium ammonium phosphate urolithiasis in cats. $\mathrm{Am}$ Vet Med Assoc 217, 520-525. 